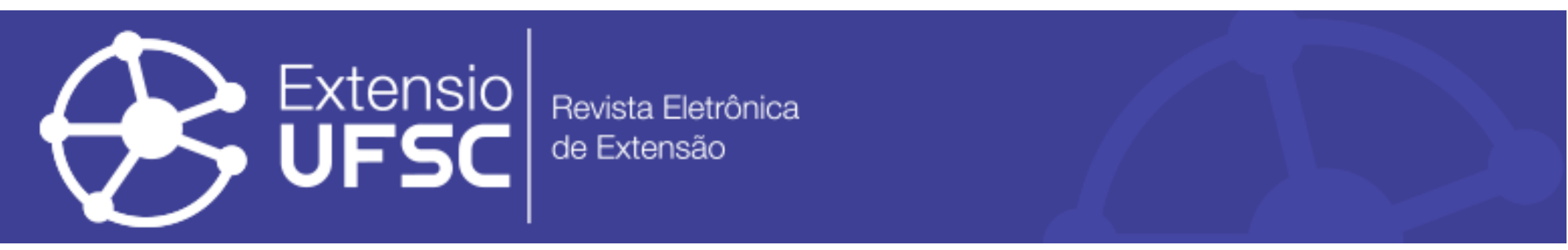

\title{
PIONEIRISMO EXTENSIONISTA NA UNIVERSIDADE DO ESTADO DO RIO GRANDE DO NORTE: CURSO À DISTÂNCIA EM PRIMEIROS SOCORROS E SUPORTE BÁSICO DE VIDA
}

\author{
Perside dos Santos Pinheiro \\ Universidade do Estado do Rio Grande do Norte \\ persidesantos@hotmail.com \\ Matheus Ferreira Feitosa \\ Universidade do Estado do Rio Grande do Norte \\ mathe.feitosa@gmail.com \\ Giulia Mendonça da Silveira \\ Universidade do Estado do Rio Grande do Norte \\ giuliamsilveira@hotmail.com \\ Nadjaneyre Linhares Casimiro \\ Universidade do Estado do Rio Grande do Norte \\ nadjaneyre@gmail.com \\ João Paulo Queiroz Cardoso Cunha \\ Universidade do Estado do Rio Grande do Norte \\ jopacunha@gmail.com \\ Nathalia Gonçalves da Silva \\ Universidade do Estado do Rio Grande do Norte \\ nathaliasjdr@yahoo.com.br
}

Camila Rafaella Nunes Alves

Universidade do Estado do Rio Grande do Norte mila_rna@hotmail.com

Vanessa Regina de Morais Universidade do Estado do Rio Grande do Norte vanessaregina95@hotmail.com

Indira Coan Zanata

Universidade do Estado do Rio Grande do Norte indiracoan@gmail.com

Mycaele Carine dos Anjos Senra Universidade do Estado do Rio Grande do Norte mycaeleanjos@gmail.com

Rafaela Dias Adami Universidade do Estado do Rio Grande do Norte rafaela.adami@gmail.com

Francisco Napoleão Tulio Varela-Barca Universidade do Estado do Rio Grande do Norte fntvbarca@yahoo.com.br

\begin{abstract}
Resumo
A extensão universitária tem como finalidade desenvolver intervenções abrangentes e impactantes na sociedade. O curso de suporte básico de vida na Universidade do Estado do Rio Grande do Norte (UERN) visa contemplar esses objetivos através da disseminação do conhecimento teórico-prático em medidas de primeiros socorros voltadas ao público em geral, por meio de uma linguagem acessível e de metodologias dinâmicas. São abordadas as situações de urgência e emergência mais frequentes em atendimento pré-hospitalar, nas quais, a intervenção precoce funciona como medida salvadora de vida por meio de aulas práticas e teóricas. Este trabalho deteve-se a mostrar como essa iniciativa vem se desenvolvendo, implantando novas modalidades de acesso à informação técnica sobre primeiros socorros, bem como todas as estratégias utilizadas no intuito de treinar efetivamente acadêmicos e leigos. o projeto está em vigor desde o ano de 2013 e, consequentemente à importância do tema, a cada ano, o número de participantes capacitados tem aumentado progressivamente, corroborando a qualidade da informação repassada e o seu respaldo perante à universidade e aos cidadãos. Nesse sentido, é imprescindível a continuidade de caráter permanente do curso, a fim de promover a importância e a atualização constante desse tema tão recorrente e negligenciado, apontando ainda, para a promoção em saúde também no ambiente virtual, levando a informação precisa a qualquer lugar do mundo com acesso à internet.

Palavras-chave: Primeiros Socorros. Suporte Básico de Vida. Extensão Comunitária. Educação à Distância.
\end{abstract}




\title{
EXTENSIONIST PIONEERING AT THE UNIVERSIDADE DO ESTADO DO RIO GRANDE DO NORTE: ONLINE COURSE IN FIRST AIDS AND BASIC LIFE SUPPORT
}

\begin{abstract}
The university's extension has as main aim to develop interventions that impact and embrace the society. The first aids and basic life support (BLS) in the UERN has as principal objective to include, by means of the dissemination of the practical and theoretical knowledge, the first aids procedures turned to the general public, by means of an accessible language and of dynamical methodologies. Conditions of urgency and emergency are presented, usually the most frequent in the pre-hospital' treatment, where precocious intervention word as the way to save lives, by means of practical and theoretical classes. This work tried to show how these initiatives have been developed, implanting new modalities of access to technical information about first aids, as well as all the used strategies to train effectively academic and not academic people. This Project have been under execution since 2013 and, consequently due to the importance of the theme, every year, the number of trained participants have been increasing, corroborating to the quality of the information presented and to the backup of the university and the citizens. In this way, it is of extremely importance the continuity of the permanent character of the course, in order to promote the importance and constant actualization in the field so neglected and recurrent, also considering, the promotion of the health in the virtual world too, bringing the information to any place in the world with internet access.
\end{abstract}

Keywords: First Aids. Basic Life Support. Communitarian Extension. Online Education.

\section{PIONERISMO EXTENSIONISTA EN LA UNIVERSIDAD DEL ESTADO DEL RIO GRANDE DO NORTE: CURSO A DISTANCIA EN PRIMEROS SOCORROS Y SOPORTE BÁSICO DE VIDA}

\begin{abstract}
Resumen
La extensión universitaria tiene como finalidad desarrollar intervenciones que abarcan y son impactantes en la sociedad. El curso de soporte básico de vida en la UERN visa contemplar eses objetivos través la diseminación del conocimiento teóricopráctico en medidas de primeros socorros direccionadas al público en general, por medio de un lenguaje accesible y de metodologías dinámicas. Son abordadas las situaciones de urgencia y emergencia más frecuentes en atendimiento prehospitalar, en las cuales, la intervención precoces funciona como medida que salvan vidas por medio de clases prácticas y teóricas. Ese trabajo detuve-se a mostrar como esa iniciativa viene se desarrollando, implantando nuevas modalidades de acceso a la información técnica sobre primeros socorros, así como todas las estrategias utilizadas con intuito de preparar efectivamente académicos y no académicos. El proyecto está hace el año de 2013 a funcionar y, consecuentemente la importancia del tema, a cada año, el número de participantes capacitados tiene aumentado progresivamente, corroborando con la cualidad de la información repasada y su respaldo delante de la universidad y a los ciudadanos. En ese sentido, es imprescindible la continuidad de carácter permanente de lo curso, para promover la importancia y la actualización constante de ese tema tan recurrente y que tiene mucha negligencia, apuntando aún, para la promoción en la salud y también en el ambiente virtual, llevando la información precisa a cualquier lugar en el mundo con acceso a internet.
\end{abstract}

Palavras-Claves: Primeros Socorros. Soporte Básico de Vida. Extensión Comunitaria. Educación à Distancia. 
Pioneirismo extensionista na Universidade do Estado do Rio Grande do Norte: curso à distância em primeiros socorros e suporte básico de vida

\section{INTRODUÇÃO}

A prática adequada dos primeiros atendimentos a vítimas em situações de urgência e emergência mostraram seus benefícios desde o início da sua aplicação, no final do século XVIII, através dos cuidados com soldados feridos nas guerras napoleônicas, porém os primeiros cuidados registrados na história da humanidade foram da parábola do bom samaritano na bíblia. Desde então, os conhecimentos foram aperfeiçoados, permitindo o treinamento de pessoas da comunidade para que pudessem atuar com eficácia no auxílio às vítimas. Isso evita a ocorrência de complicações e sequelas, também prevenindo danos às pessoas que prestam auxílio, resultado do impulso e desespero em querer ajudar (AGUIAR et al. 2018, FERREIRA JUNIOR et al. 2018, GOMES et al. 2016).

A tríade composta por ensino, pesquisa e extensão, formam o tripé universitário e o conhecimento adquirido na pesquisa é colocado em prática na extensão, sendo executado pela atividade, pelo pesquisador, estudantes e população. O curso suporte básico de vida preenche as lacunas que o ensino público possui e leva o conhecimento sobre primeiros socorros às pessoas comuns (MENEGON et al., 2015).

A visão do atendimento primário de vítimas em situações de risco revela-se de extraordinária importância em todos os segmentos da sociedade, e na universidade quanto a complementação dos programas curriculares da mesma. O curso de suporte básico de vida oferece preparação para o enfrentamento dos mais diversos tipos de situações como em quadros de urgência e emergência como queimaduras, paradas cardiorrespiratórias, traumas, entre outros acontecimentos, proporcionados nas mais demasiadas áreas de atuação (AGUIAR et al. 2018, FERREIRA JUNIOR et al. 2018, GOMES et al. 2016, KAWAKAME \& MIYADAHIRA 2015, KNOPFHOLS et al, 2015).

Dessa forma, visando a priori complementação do ensino superior, o curso de suporte básico de vida foi elaborado e executado por professores e alunos, junto ao Departamento de Educação Física da Universidade do Estado do Rio Grande do Norte (UERN). Este curso possui sua versão presencial e, em 2016, foi elaborada a sua parte à distância, que se dá através de uma plataforma online, que contém elementos textuais utilizados no curso presencial e exercícios para a certificação do aprendizado, ofertando assim um ensino que compreende um melhor atendimento de urgência e emergência no ambiente pré-hospitalar, o qual abrange a sociedade acadêmico- 
Pioneirismo extensionista na Universidade do Estado do Rio Grande do Norte: curso à distância em primeiros socorros e suporte básico de vida

científica e a comunidade em geral. O curso acontece de forma ininterrupta, desde 2013 na sua forma presencial e desde 2016 na modalidade a distância, com grande sucesso, ambos abordando temas como a imobilização de vítimas, traumas, crises epiléticas, paradas cardiorrespiratórias, hemorragias, retirada de capacete, engasgamento, aplicações intramusculares, entre outros (VARELA-BARCA et al., 2016; CUNHA et al., 2016).

\section{MATERIAIS E MÉTODOS}

O curso de Suporte Básico de Vida (SBV) teve duas vertentes não-habituais de sua execução no segundo semestre de 2017. Uma forma presencial e outra à distância. Ambos com duração semestral. A última edição presencial e de forma similar a outras edições foi realizada junto as dependências da Faculdade de Ciências e Saúde da Universidade do Estado do Rio Grande do Norte (FACS-UERN), onde aulas teórico-práticas foram oferecidas aos sábados, no turno matutino e vespertino, no Corpo de Bombeiro Militar (CBM-RN), e na Unidade de Pronto Atendimento (UPA), do bairro do Alto de São Manoel em Mossoró - RN (VARELA-BARCA et al., 2016; CUNHA et al., 2016). O curso foi aberto para população em geral, não houve limitação do número de vagas, sendo pré-requisito básico o domínio da língua portuguesa para a participação, visando ter um maior número de inscritos e maior difusão das técnicas.

Os participantes do curso presencial foram treinados, por meio de simulações práticas e oficinas, para realizar as formas apropriadas de abordagem a uma vítima em situações potenciais de risco de morte. Para a realização de treinamentos de Ressuscitação Cardiopulmonar (RCP), manobras de desobstrução de vias aéreas e retirada de capacetes, foram utilizados três manequins: um adulto, um adolescente e um infantil, que simulou um bebê, além dos próprios participantes do curso que ora assumiam papel de socorrista e ora de vítima, sem colocar em risco a vida dos mesmos. Os instrumentos necessários utilizados em abordagens que simulavam atendimento às vítimas incluem: esfigmomanômetros, oxímetros, estetoscópios e máscaras de silicone para reanimação, bem como ataduras para realização de torniquetes e prática de injetáveis com cadáveres cedidos pela instituição.

Três monitores voluntários e três bolsistas do Programa Institucional de Bolsas de Extensão Universitária (PIBEX) auxiliaram na apresentação e execução das aulas expositivas e práticas, bem como na elaboração do curso à distância de SBV e Primeiros Socorros. A plataforma adotada pelo 
Pioneirismo extensionista na Universidade do Estado do Rio Grande do Norte: curso à distância em primeiros socorros e suporte básico de vida

Departamento de Ensino à Distância da UERN, é o Moodle. A alimentação e edição do Moodle vem sendo regularmente executada pelo coordenador do curso presencial.

Foram elaboradas onze aulas para o curso à distância ofertadas em três modalidades: gratuita, paga com certificação 30 horas ou paga com certificação de 60 horas. O curso pago com certificação de 60 horas ainda contou com aulas práticas presencias na FACS. Cada aula era composta por vídeoaulas, textos, atividades e referencial teórico de suporte para estudos. Os temas abordados são: Acidente Vascular Cerebral (AVC); crises convulsivas; paradas cardiorrespiratórias (PCR); Ressuscitação Cardiopulmonar (RCP) em adultos, crianças e bebês; trauma: abdominal, crânio encefálico, membros e tórax; afogamento e eletrocussão. As vídeo aulas foram produzidas nas salas de aula da FACS com uso de câmeras simples de aparelhos de celulares convencionais, e editadas pelos próprios monitores. A atividade final que garantia a certificação inclui a produção de um texto descritivo-explicativo sobre cada um dos assuntos abordados durante o curso.

Foram selecionados artigos do banco de dados das plataformas Scielo, NCBI (PubMed) e LILACS para a confecção e embasamento desse artigo e dos textos dos cursos presenciais e à distância.

\section{RESULTADOS E ANÁLISES}

As visitas ao $2^{\circ}$ Subgrupo do Corpo de Bombeiros Militar de Mossoró contribuíram para aperfeiçoar os aspectos práticos do curso e proporcionar a vivência da realidade dos profissionais que atuam com Suporte Básico de Vida (SBV) e Primeiros Socorros. Além disso, as visitas à Unidade de Pronto Atendimento (UPA) Alto de São Manoel permitiram maior assimilação e integração do ensino aprendizagem a partir da vivência da abordagem de procedimentos e intervenções na atuação teórico-prática dos profissionais da saúde com Suporte Básico de Vida. Diante disso é de grande valia que o curso continue sendo ministrado semestralmente, como vem ocorrendo. Outros cursos de Suporte Básico de Vida já foram ofertados pela UERN, porém com população-alvo diferenciada, sendo essa os vigilantes atuantes na universidade.

As inscrições para a primeira turma do curso ocorreram em 2013, somente com curso teórico com o preenchimento total das vagas disponíveis, sendo 10 o número de inscritos, no entanto apenas 8 concluíram. A maioria desses alunos cursavam bacharelado em Educação Física na UERN. Em 2014 também foi da mesma forma, porém das 10 vagas ocupadas houve a integralização de 
Pioneirismo extensionista na Universidade do Estado do Rio Grande do Norte: curso à distância em primeiros socorros e suporte básico de vida

indivíduos de outros cursos além de Educação Física, como Medicina, Física e Química, sendo que 2 desses desistiram. Já em 2015, houve a expansão para o dobro das vagas, por exigência em reunião departamental, sendo assim, dos 20 inscritos 12 finalizaram o curso. A partir de então ampliou-se cada vez mais o número de vagas ofertadas e de concluintes, além disso a maioria dos integrantes passaram a ser acadêmicos de medicina, apesar da ampla divulgação semestral. Em 2016, foram inscritos o dobro dos números de pessoas da edição anterior, totalizando 40 inscritos, dos quais 29 finalizaram, em 2017, apesar do número de inscritos ter permanecido praticamente constante, sendo 42 inscritos, o número de concluintes aumentou para 32 alunos (VARELA-BARCA et al., 2016; CUNHA et al., 2016).

Vale ressaltar que, nas edições de 2013 e 2014 a carga horária era de 30 horas em sala de aula, além de que era exigido a elaboração de um projeto científico de conclusão de curso pertencente à área de urgência e emergência como modalidade de avaliação e, se aprovado, equivaleriam a mais 30 horas de atividades. No entanto, a partir de 2015, a carga horária de frequência efetiva em sala de aula passou a ser de 60 horas, associada a execução de um projeto de conclusão de curso, mas que não contabilizaria como carga horária. Sendo em ambas as cargas horárias citadas aceitável 25\% de faltas, dessa forma com a extensão da carga horária, tornou-se possível menos pessoas deixarem de concluir pelo número de faltas (VARELA-BARCA et al., 2016; CUNHA et al, 2016).

Diante da importância da temática e do aumento da procura, no período de 2016-2017, o curso dispôs de três estudantes bolsistas participantes do PIBEX, os quais elaboraram um Curso de Suporte Básico de Vida à distância, em parceria com a Pró-Reitoria de Extensão (PROEX), Departamento de Ensino à Distância (DEaD) e a FUNCITERN. O curso passou por sua primeira execução no ano de 2017, com expressiva matrícula de alunos.

O curso à distância está no portal do Departamento de Ensino à Distância (DEaD) sob o seguinte endereço eletrônico: http://dead.uern.br/moodle/login/index.php. Para acessar, é necessário cadastro prévio com o Departamento de Ensino à Distância, além da comunicação através do e-mail já preparado para tal suporte: sbv.uern@gmail.com. O curso conta com vídeoaulas, textos, atividades e referencial teórico de suporte para estudos. Desse modo tornou-se possível ampliar o alcance da informação, antes restrita à comunidade acadêmica, para o público de modo geral. No momento o curso é composto por 11 módulos de condutas em Suporte Básico de Vida, incluindo Acidente Vascular Cerebral (AVC), crises convulsivas, paradas cardiorrespiratórias (PCR), Ressuscitação Cardiopulmonar (RCP) em adultos, Ressuscitação Cardiopulmonar (RCP) em 
Pioneirismo extensionista na Universidade do Estado do Rio Grande do Norte: curso à distância em primeiros socorros e suporte básico de vida

crianças, Ressuscitação Cardiopulmonar (RCP) em bebês, trauma abdominal, trauma crânio encefálico (TCE), trauma de membros, trauma de tórax, afogamento e eletrocussão. Três modalidades são ofertadas: curso gratuito presencial, curso à distância, pago e com certificação de 30h e aulas práticas em Mossoró na UERN, pago e com certificação de 60h. Na primeira turma da modalidade à distância e certificação de 60h, totalizaram 153 participantes de todo o estado do Rio Grande do Norte. Toda a verba adquirida com o curso à distância será destinada ao autofinanciamento futuro de alunos estipendiados ou ainda a provável construção de laboratório específico pra primeiros socorros no campus central.

Pretendemos oferecer o curso semestralmente e atingir cada vez mais indivíduos, pois o curso à distância é capaz de levar aprendizagem e atualização necessários para exercer um papel transformador na sociedade e, principalmente para amparar as vítimas que dependem dos conhecimentos dos outros em SBV para sair de uma situação de risco de morte.

O curso de Suporte Básico de Vida é aberto ao público, tendo como critério de inclusão saber ler e escrever em língua portuguesa, haja vista seu objetivo primordial: a capacitação para o atendimento inicial às vítimas de eventos que possam representar risco de morte, similar a cursos já ofertados no país e que se enquadram perfeitamente no conceito de extensão (PEREIRA et al., 2015; SILVA et al., 2016; TAVARES et al., 2015; TOMAZINI et al., 2018.

Todavia, na modalidade presencial, observa-se uma prevalência de acadêmicos do curso de graduação em Medicina da UERN, nos últimos anos de graduação, provavelmente pela necessidade individual de aprender e desenvolver as habilidades profissionais, adquirindo competências técnicas para o exercício de uma atividade profissional mais qualificada. Ademais, o fato de as aulas da referida modalidade serem ofertadas nas dependências da Faculdade de Ciências da Saúde (FACS) pode também explicar a supremacia no número daqueles graduandos, tal preferência foi dada pela importante lacuna existente no início do curso de Medicina, referente a abordagem básica dos primeiros socorros a pacientes.

A cada edição, o número de inscritos foi maior em comparação à anterior, uma vez que não se limitou a quantidade de vagas ofertadas. Entretanto, o total de concluintes foi sempre menor do que o de inscritos. Não se pode afirmar o real motivo das evasões, porém, acredita-se que a alta carga-horária dos cursos de graduação associada a outras atividades extracurriculares possam gerar uma sobrecarga, além do entusiasmo de participar do curso e desapontamento pelo fato de 
Pioneirismo extensionista na Universidade do Estado do Rio Grande do Norte: curso à distância em primeiros socorros e suporte básico de vida

exigências serem cobradas, já que no curso à distância também foi observado um número de concluintes inferior ao número de inscritos.

Durante o processo de construção e desenvolvimento do curso de Suporte Básico de Vida, além da capacitação dos alunos participantes foi possibilitado aos monitores o aprendizado no que diz respeito à condução e gerenciamento de projetos de extensão, reforçando a função social da universidade perante a comunidade em que está inserida, bem como fomentando a extensão, um de seus pilares (MENEGON et al., 2015). Além disso, o curso integrou alunos e monitores à realidade da atividade profissional futura, permitindo-os simular situações que possivelmente serão vivenciadas em seus campos de trabalho. A implementação do projeto, além de permitir a todos os envolvidos uma oportunidade de aperfeiçoar suas habilidades quanto ao socorro das vítimas, evidencia sua responsabilidade dentro da comunidade em que estão inseridos, possibilitando aos participantes inúmeras vivências que complementam as teorias abordadas em salas de aula. Os alunos, portanto, expandem seus horizontes e aperfeiçoam seu senso-crítico na busca da elaboração e apropriação do conhecimento significativo. Uma vez preparados, os concluintes podem atuar como agentes de propagação do conhecimento em primeiros socorros, prolongando o tempo de vida das vítimas para que assim possam chegar aos locais de suporte avançado de vida, que é restrito aos médicos e profissionais da saúde que compõem a equipe (OLIVEIRA et al 2018). Concomitante ao apoio dado ao professor coordenador do curso de SBV no que diz respeito à execução do curso presencial, os monitores elaboraram os textos e os vídeos dos módulos oferecidos no curso à distância, que atualmente encontra-se em andamento.

A procura pelo curso à distância foi superior àquela relacionada ao presencial, provavelmente pela praticidade de poder adquirir o conhecimento dentro da sua própria casa, sem a necessidade de deslocamento. A divulgação do curso online, por ser feita através de anúncios publicitários, redes sociais, anúncios publicitários da Diretoria de Educação à Distância (DEaD) da UERN, no meio eletrônico e divulgação na universidade atingiu um público maior do que a divulgação exclusiva nas dependências da UERN. Por fim, é notório que a versão à distância melhor atende às necessidades de cada indivíduo, devido a flexibilidade e a possibilidade de adaptar o horário destinado às aulas, não comprometendo outras atividades e compromissos que porventura existam (SILVA et al., 2016). 
Pioneirismo extensionista na Universidade do Estado do Rio Grande do Norte: curso à distância em primeiros socorros e suporte básico de vida

\section{CONSIDERAÇÕES FINAIS}

Este projeto extensionista Suporte Básico de Vida vem sendo realizado na UERN desde 2013, e tem qualificado e capacitado pessoas com interesse em saber dar assistência às vítimas em situações emergenciais. Constata-se que a grande maioria dos participantes, até 2017, foram acadêmicos da própria instituição (estudantes de Física, Biologia, Medicina, Enfermagem, de universidades particulares, técnicos de laboratório), e hoje não se encontram mais vinculados a suas instituições. A cada nova edição, o curso é atualizado e aperfeiçoado, para permitir uma capacitação direcionada e adequada aos futuros socorristas.

O projeto dará continuidade a parcerias com outros serviços com experiência na assistência de abordagem de vítimas em situações emergenciais. Da mesma forma tem por objetivo ampliar o curso à distância, fazendo inclusão de novos temas, vídeos e recursos que permitam a instrução mais completa dos participantes para realizar a assistência imediata em condições necessárias, bem como a inserção de intérprete pra Língua Brasileira de Sinais (LIBRAS), a fim de possibilitar a inclusão de pessoas surdas. Ademais, importante é destacar a intenção de que haja tradução pra outros idiomas, no futuro próximo (inglês, francês, alemão e espanhol). Pretende-se renovação da qualidade de vídeos com parceria do sistema televisivo e o Departamento de Comunicação da própria instituição. Portanto, esta atividade de extensão é indispensável, única e de extrema importância, visto que o curso tem natureza de instruir os participantes para situações que precisam de medidas ágeis e que são imprescindíveis para que se salve vidas, que diminuam a incapacidade e minimizem o sofrimento.

\section{REFERÊNCIAS}

AGUIAR, A. C. L. et al. Blog como ferramenta educacional: contribuições para o processo interdisciplinar em saúde. Rev Eletron Comun Inf Inov Saúde. V.12, n.2, p. 220-31, 2018.

CUNHA, J.P.Q.C. et al. Suporte Básico de Vida na UERN: Novas perspectivas na atividade. In: III Fórum de Extensão do Oeste Potiguar, 2016, Mossoró. Anais. 369-373.

FERREIRA JUNIOR, M. P. et al. conhecimento do corpo de bombeiros militar sobre ressuscitação cardiopulmonar. Rev enferm UFPE, v.12, n.1, p.118-27, 2018. 
Pioneirismo extensionista na Universidade do Estado do Rio Grande do Norte: curso à distância em primeiros socorros e suporte básico de vida

GOMES, M. P. et al. Projeto viva coração: relato de experiência. Revista Baiana de Enfermagem. Salvador, v.30, n.4, p.1-10, 2016.

KAWAKAME, P. M. G.; MIYADAHIRA, A. M. K. Avaliação do processo ensino-aprendizagem de estudantes da área da saúde: manobras de ressuscitação cardiopulmonar. Rev Esc Enferm USP. v.49, n.4, p.657-664, 2015.

KNOPFHOLS, J. et al. Capacidade de manuseio da parada cardíaca em locais de alto fluxo de pessoas em Curitiba. Rev Soc Bras Clin Med. v.13, n.2, p.114-8, 2015.

MENEGON, R. R. et al. A Importância dos Projetos de Extensão no Processo de Formação Inicial de Professores de Educação Física. In: 14ª Jornada do Núcleo de Ensino de Marília, Anais. 01-12, Marília. 2015.

OLIVEIRA, S. F. G. et al. Conhecimento de parada cardiorrespiratória dos profissionais de saúde de um hospital público: estudo transversal. Rev Pesq Fisio. v.8, n.1, p.101-109, 2018.

PEREIRA, K. C. et al. A construção do conhecimento sobre prevenção de acidentes e primeiros socorros por parte do público leigo. R. Enferm. Cent. O. Min. V.5, n. 1, p.1478-1485, 2015.

SILVA, L. T. C. et al. Percepções de estudantes de enfermagem sobre educação à distância. Ciencia y Enfermeria v.22, n.2, p.129-139, 2016.

TAVARES, L. F. B. et al. Conhecimento de estudantes de graduação em ciências da saúde em testes objetivos sobre suporte básico de vida. Journal of Human Growth and Development, v.25, n.3 p.397-306. 2015.

TOMAZINI, E. A. S. et al. Curso on-line sobre suporte avançado de vida em parada cardiorrespiratória: inovação para educação permanente. Rev Rene. v.19, p32444, 2018.

VARELA-BARCA, F.N.T. et al. Suporte Básico de Vida na UERN: Uma Atividade Extensionista. Rev. Extendere. v.4, n.1, p.27-36, 2016.

Recebido em: 21/11/2017

Aceito em: 14/03/2019 